\title{
NILAI EKONOMI KARBON HUTAN RAWA GAMBUT MERANG KEPAYANG, PROPINSI SUMATERA SELATAN \\ (Economic Value of Carbon of Merang Kepayang Peat Swamp Forest, South Sumatera Province)
}

\author{
Nur Arifatul Ulya ${ }^{1,2, *}$, Sofyan P. Warsito ${ }^{3}$, Wahyu Andayani ${ }^{3}$ dan Totok Gunawan ${ }^{4}$ \\ ${ }^{1}$ Program Doktoral Program Studi Ilmu Kehutanan, Universitas Gadjah Mada, \\ Bulaksumur, Yogyakarta 55281. \\ ${ }^{2}$ Balai Penelitian Kehutanan Palembang, Jl. Kol. H. Burlian Km. 6,5 Punti Kayu, Palembang. \\ ${ }^{3}$ Fakultas Kehutanan, Universitas Gadjah Mada, Bulaksumur, Yogyakarta 55281. \\ ${ }^{4}$ Fakultas Geografi, Universitas Gadjah Mada, Bulaksumur, Yogyakarta 55281. \\ *Penulis korespondensi. No Tel/Fax: 0711-414864. Email: nur_arifa@yahoo.com.
}

Diterima: 15 Mei 2014

Disetujui: 29 September 2014

\begin{abstract}
Abstrak
Hutan rawa gambut menyimpan cadangan karbon baik di tanah maupun di atas tanah. Hutan Rawa Gambut Merang Kepayang (HRGMK) merupakan kawasan hutan yang berada di kubah gambut terbesar di Sumatera Selatan, yaitu Kubah Gambut Merang (KGM), yang didalamnya terdapat gambut dengan ketebalan lebih dari 3 meter. Meskipun menurut aturan KGM seharusnya dikonservasi, pada kenyataannya kawasan HRGMK dihadapkan pada konversi. Konversi HRGMK diduga akan mengakibatkan terganggunya fungsi hutan rawa gambut sebagai cadangan karbon dunia sehingga akan menyebabkan terjadinya emisi karbon ke atmosfer dalam jumlah besar. Penelitian ini bertujuan untuk mengetahui nilai ekonomi kawasan HRGMK sebagai penyimpan cadangan karbon. Hasil penelitian diharapkan menjadi acuan pelestarian HRGMK sebagai stabilisator iklim dunia. Nilai ekonomi karbon HRGMK ditaksir dengan menggunakan harga bayangan. Harga karbon yang digunakan untuk menaksir nilai ekonomi karbon diperoleh dengan metode benefit transfer. Hasil penelitian menunjukkan bahwa nilai total karbon HRGMK adalah US\$ 1.591.878.378,00 atau Rp. 14.002.162.211.645,00. Nilai tersebut sebagian besar berasal dari cadangan karbon di bawah tanah.
\end{abstract}

Kata kunci: gambut, hutan, karbon, nilai ekonomi, rawa.

\section{Abstract}

Peat swamp forests store aboveground and belowground carbon. Merang Kepayang Peat Swamp Forest (MKPSF) is a forest area which is located in Merang Peat Dome (MPD), the largest peat dome in South Sumatra, with peat thickness more than 3 meters. Although the order should be conserved MPD, in fact MKPSF area exposed to the conversion. MKPSF conversion would presumably result in impaired function of peat swamp forest as world's carbon storage that will be caused carbon emissions into the atmosphere in large quantities. This study aimed to determine the economic value of the HRGMK as carbon storage. The results are expected to be justifications for conservation of MKPSF as climate stabilizers. The economic value of carbon HRGMK assessed using shadow pricing method. The carbon price used to assess the economic value of carbon derived by benefit transfer method. The results showed that the total carbon value of HRGMK is U.S. \$ 1,591,878,378.00 or Rp. 14,002,162,211,645.00. This value is largely derived from belowground carbon.

Keywords: carbon, economic value, forest, peat, swamp.

\section{PENDAHULUAN}

Luas sumber daya gambut di Indonesia menurut Pusat Penelitian Tanah (1981) dalam Wahyunto dkk. (2005) adalah 27,06 juta hektar. Propinsi Sumatera Selatan merupakan propinsi dengan kawasan gambut terluas ke-dua di Pulau Sumatera setelah Propinsi Riau (Wahyunto dkk., 2005). Lahan gambut di Propinsi Sumatera Selatan tersebar di sepanjang pantai timur Sumatera Selatan.

Lahan gambut merupakan ekosistem lahan basah yang dibentuk oleh adanya akumulasi bahan organik di lantai hutan yang berasal dari reruntuhan vegetasi di atasnya dalam kurun waktu lama. Akumulasi ini terjadi karena kelambatan laju dekomposisi dibandingkan dengan laju penimbunan bahan organik di lantai hutan yang basah atau tergenang. Seperti gambut tropis lainnya, gambut di Indonesia dibentuk oleh akumulasi residu vegetasi tropis yang kaya akan kandungan lignin dan nitrogen. Proses dekomposisi yang lambat menyebabkan pada ekosistem rawa gambut masih dapat dijumpai batang, cabang dan akar besar (Murdiyarso dkk., 2004). 
Residu vegetasi tropis dalam kondisi tertimbun di lahan hutan yang basah merupakan cadangan karbon terestrial. Lahan gambut tropika merupakan cadangan karbon terestrial yang penting untuk diperhitungkan. Lahan gambut menyimpan antara 15 sampai 25\% dari karbon dan nitrogen terestrial yang ada di dunia (Batjes, 1996). Wahyunto dkk., (2005) mengasumsikan jika kedalaman rata-rata gambut di seluruh Indonesia adalah 5 meter, bobot isi $114 \mathrm{~kg}$ per $\mathrm{m}^{3}$ dan luasnya 16 juta ha, maka cadangan karbonnya adalah 16 giga ton.

Hutan Rawa Gambut Merang Kepayang (HRGMK) merupakan hutan rawa gambut alami yang masih tersisa di pantai timur Propinsi Sumatera Selatan (Murdiyarso dkk., 2007). HRGMK berlokasi di Kubah Gambut Merang yang merupakan kubah gambut terbesar di Sumatera Selatan (Ballhorn dkk., 2007). Hasil survey menunjukkan bahwa di kawasan tersebut banyak ditemukan gambut dengan kedalaman lebih dari 3 meter (Anonim, 2004).

Hutan rawa gambut dalam kondisi alami merupakan cadangan karbon terestrial yang penting. Dalam kondisi terganggu hutan rawa gambut akan menjadi sumber emisi karbon dalam jumlah besar baik yang berasal dari vegetasi di atas tanah maupun di tanah yang berupa lahan gambut. Emisi karbon pada lahan gambut sangat dipengaruhi oleh tata guna lahan, kelembaban tanah dan aplikasi pupuk (Hadi dkk., 2000; Hadi dkk., 2001) serta kondisi hidrologis (Hadi dkk., 2005; Furukawa dkk., 2005). Selanjutnya Murdiyarso dan Wasrin (1995) menyatakan bahwa konversi hutan di dataran rendah (termasuk hutan rawa gambut) menjadi lahan pertanian menghasilkan emisi karbon sebesar 0,33 giga ton $C$ per tahun. Kemampuan hutan rawa gambut alami dalam menyimpan cadangan dihadapkan pada konversi untuk kepentingan sektor kehutanan maupun non kehutanan dalam rangka pembangunan.

Konversi terjadi karena hutan rawa gambut alami dianggap tidak memberikan manfaat finansial apabila dibandingkan dengan kawasan budidaya. Hooijer dkk. (2006) menyatakan bahwa konversi hutan alam rawa gambut menjadi kawasan budidaya menyebabkan dampak lingkungan yang terjadi karena adanya proses persiapan lahan untuk budidaya kelapa sawit di lahan gambut. Agus dan Subiksa (2008) menambahkan bahwa budidaya pertanian di lahan gambut membutuhkan pengaturan tinggi muka air yang menyebabkan terjadinya drainase gambut. Selain itu, pembangunan perkebunan kelapa sawit di lahan gambut umumnya menyebabkan terjadinya kebakaran atas gambut dan dekomposisi biomassa vegetasi awal.
Hutan rawa gambut alami mempunyai peranan penting dalam menjaga kualitas lingkungan hidup melalui kemampuannya dalam menyimpan cadangan karbon. Gangguan terhadap HRGMK akan berdampak pada penurunan kualitas lingkungan hidup manusia, sehingga pengelolaan HRGMK harus didasari oleh pertimbangan yang komprehensif. Aspek ekonomi merupakan salah satu aspek yang harus dipertimbangkan dalam perumusan rencana pengelolaan HRGMK. Nilai ekonomi cadangan karbon hutan rawa gambut harus diketahui agar pertimbangan pengelolaan kawasan hutan terutama yang dihadapkan pada konversi mempunyai dasar pertimbangan ilmiah yang lebih komprehensif.

Penelitian ini bertujuan untuk menaksir nilai ekonomi Hutan Rawa Gambut Merang Kepayang. Hasil penelitian ini diharapkan dapat dipergunakan sebagai acuan dalam perumusan kebijakan pengelolaan hutan terutama untuk kawasan HRGMK dan sekitarnya. Kebijakan pengelolaan hutan dengan mempertimbangkan jasa lingkungan yang diberikan oleh sumberdaya hutan dalam bentuk kemampunannya dalam menyimpan cadangan karbon diharapkan bisa menghasilkan pembangunan berwawasan lingkungan dalam rangka mewujudkan pembangunan berkelanjutan.

\section{METODE PENELITIAN}

\section{Lokasi Penelitian}

Penelitian dilaksanakan di kawasan Hutan Rawa Gambut Merang Kepayang (HRGMK) yang termasuk dalam Kelompok Hutan Merang. Kawasan HRGMK berada di Kubah Gambut Merang (KGM), di sekitar Sungai Merang dan Kepayang. Kawasan ini secara administratif terletak di Kabupaten Musi Banyuasin, Provinsi Sumatera Selatan, secara astronomis terletak antara $1^{\circ} 45^{\prime}-2^{\circ} 03^{\prime}$ Lintang Selatan dan $103^{\circ} 51^{\prime}-104^{\circ} 17^{\prime}$ Bujur Timur (Gambar 1).

Lokasi ini dipilih berdasarkan fakta bahwa di kawasan ini terdapat lapisan gambut dengan kedalaman lebih dari 3 meter, sementara pengelolaan kawasan adalah sebagai Hutan Produksi (HP) dan Areal Penggunaan Lain (APL). Keputusan Presiden No. 32 Tahun 1990 tentang Pengelolaan Kawasan Lindung dan Peraturan Pemerintah No. 26 tahun 2008 tentang Rencana Tata Ruang Wilayah Nasional (RTRWN) menyatakan bahwa tanah bergambut dengan ketebalan 3 meter atau lebih yang terdapat di bagian hulu sungai atau rawa merupakan kawasan yang dilindungi. Bahkan dalam Peraturan Pemerintah No. 13 tahun 2012 tentang Rencana 


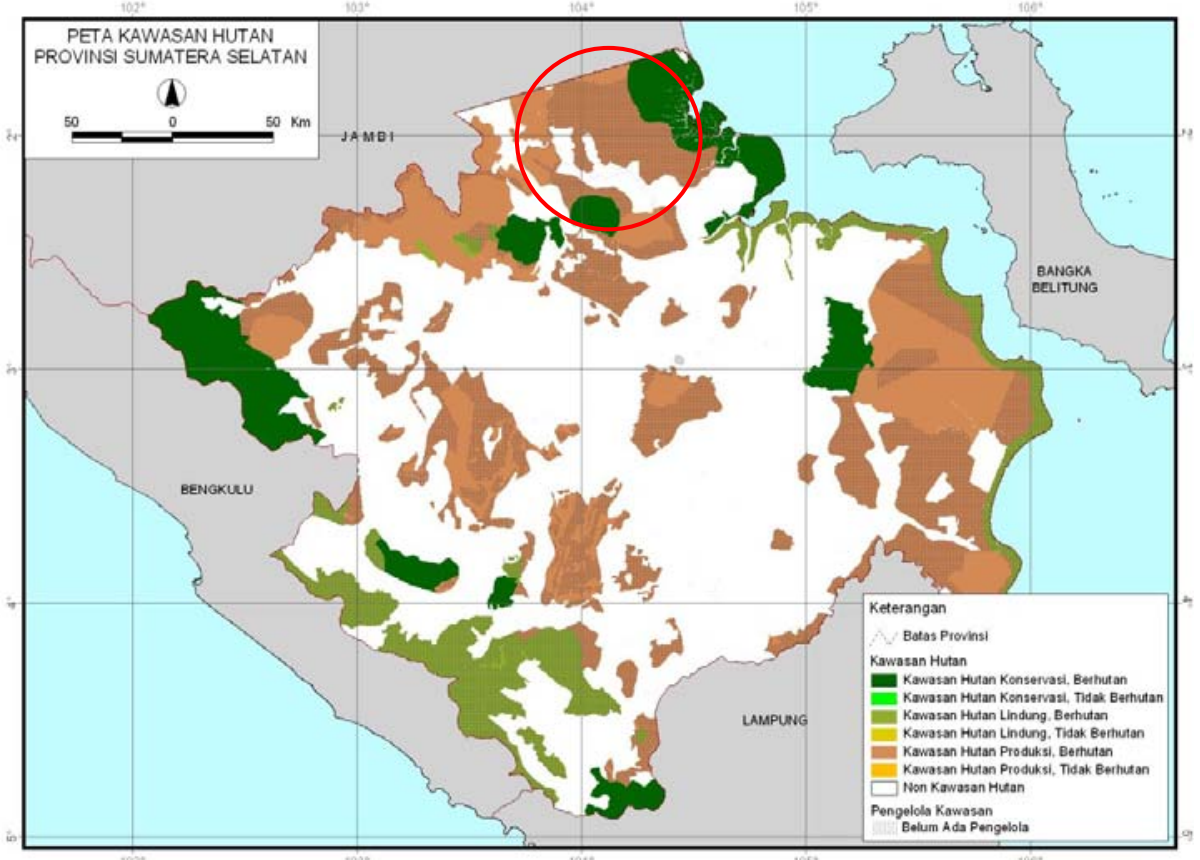

Gambar 1. Letak HRGMK di Provinsi Sumatera Selatan.

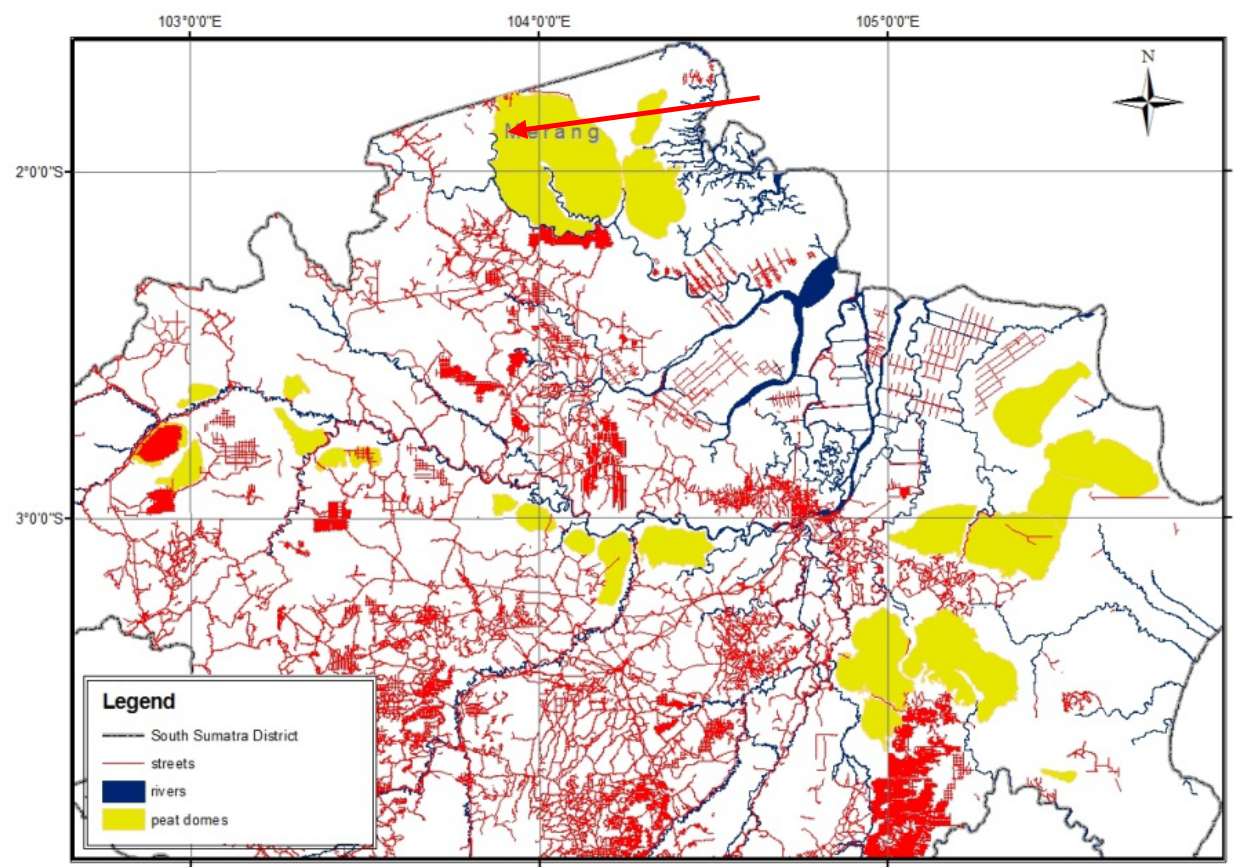

Gambar 2. Sebaran kubah gambut di Sumatera Selatan (Sumber : Ballhorn dkk., 2007).

Tata Ruang Pulau Sumatera yang merupakan perincian dari RTRWN dinyatakan bahwa kawasan bergambut Merang ditetapkan sebagai kawasan bergambut yang bernilai konservasi tinggi. HRGMK berada di kubah gambut Merang yang merupakan kubah gambut terbesar di Sumatera Selatan (Gambar 2).

\section{Pengumpulan Data}

Data penelitian ini diperoleh dari instansi pemerintah terkait, perusahaan pemegang
IUPHHK-HTI, lembaga swadaya masyarakat, kegiatan-kegiatan yang berlokasi di HRGMK dan studi pustaka. Data kedalaman gambut dan kandungan karbon mengacu pada (Ballhorn dkk., 2007; Moder dkk., 2008). Data tersebut merupakan hasil pengukuran langsung di lapangan, sehingga memiliki keakuratan tinggi dan termasuk dalam Tier 3 (Anonim, 2006; Solichin, 2010). Tier adalah tingkat kerincian faktor emisi perubahan cadangan karbon. Tier 1 tidak memerlukan pengukuran di lapangan. Tier 2 menggunakan data-data yang 
diperoleh dari penelitian di tingkat nasional, sedangkan Tier 3 yaitu pengukuran langsung di lokasi proyek (Anonim, 2006).

\section{Analisis Data}

Cadangan karbon hutan rawa gambut ditaksir nilai ekonominya dengan menggunakan metode harga bayangan (shadow pricing). Harga karbon yang digunakan diperoleh dengan benefit transfer (Breaux dkk., 1995; Pirard, 2005; Plummer, 2009). Harga karbon yang digunakan sebagai acuan adalah harga perdagangan karbon di Ulu Masen. Alasan dipilihnya harga karbon Ulu Masen sebagai acuan dalam benefit transfer adalah kesamaan lokasi, yaitu di Indonesia. Nilai ekonomi diperoleh dengan mengalikan besarnya angka cadangan karbon dengan harga karbon dalam perdagangan karbon pada luasan dan periode waktu tertentu.

\section{HASIL DAN PEMBAHASAN}

Luas HRGMK adalah 138.200 hektar (Ballhorn dkk., 2007). Tutupan lahan di HRGMK sebagian besar (88\%) adalah hutan rawa primer (Anonim, 2011). Status HRGMK merupakan hutan produksi. Di HRGMK terdapat dua bentuk tata guna lahan yaitu Hutan Produksi (HP) dan Areal Penggunaan Lain (APL). Kawasan APL di HRGMK dikelola sebagai perkebunan kelapa sawit dan pengeboran minyak.

Kubah Gambut Merang seluas 138.200 hektar memiliki kedalaman gambut rata-rata 1,26 meter, di beberapa tempat dijumpai kedalaman gambut sampai 4 meter bahkan 5,5 meter (Ballhorn dkk., 2007). Kematangan gambut di bagian atas adalah fibrik sedangkan pada lapisan yang lebih dalam lebih beragam yaitu fibrik, hemik dan saprik. Kondisi tanah masam sampai sangat masam dengan pH 4,51 sampai 4,98. Kondisi hidrologi di lokasi penelitian sangat dipengaruhi oleh Sungai Merang, Sungai Lalan dan anak sungainya (Anonim, 2008). Adapun karakteristik tutupan lahan di KGM disajikan pada Tabel 1.

Kandungan karbon hutan rawa gambut tidak hanya terdapat pada vegetasi di atas tanah (biomassa di atas tanah/aboveground biomass) melainkan juga pada tempat pertumbuhan / tanah gambut (biomassa di tanah/belowground biomass), karena tanah gambut juga merupakan bahan organik yang mengandung karbon. Perhitungan kandungan karbon KGM mengacu pada hasil perhitungan yang dilakukan oleh Ballhorn dkk. (2007) dengan menggunakan three-dimensional bed rock model yang digabungkan dengan hasil pengeboran gambut di 80 titik. Hasil perhitungan kandungan karbon di Kubah Gambut Merang disajikan pada Tabel 2. Kandungan karbon HRGMK disajikan pada Tabel 3. Sebagian besar kandungan karbon di HRGMK berasal dari biomassa di tanah yang tidak lain adalah pada Kubah Gambut Merang (KGM).

Harga karbon yang digunakan dalam perhitungan nilai ekonomi karbon HRGMK diperoleh dengan metode benefit transfer. Harga karbon yang digunakan sebagai acuan adalah harga perdagangan karbon di Ulu Masen. Harga karbon Ulu Masen adalah US\$ 4 per ton emisi $\mathrm{CO}_{2}$ yang dapat dicegah (Putro, 2008; Anonim, 2011). Asumsi nilai tukar satu US\$ adalah Rp. 9.250,00. Nilai karbon HRGMK disajikan pada Tabel 4.

Tabel 1. Karakteristik kandungan karbon berdasarkan penutupan lahan di HRGMK.

\begin{tabular}{lrrr}
\hline \multicolumn{1}{c}{ Jenis penutupan lahan } & Luas (ha) & $\begin{array}{c}\text { Kandungan karbon } \\
\text { (ton } \mathrm{CO}_{2} / \mathrm{ha} \text { ) }\end{array}$ & $\begin{array}{r}\text { Kandungan karbon } \\
\text { (ton } \mathrm{CO}_{2} \text { ) }\end{array}$ \\
\hline Air & 158 & 0 & 0 \\
Belukar & 1.737 & 30 & 52.115 \\
Belukar rawa & 3.510 & 30 & 105.293 \\
Hutan mangrove sekunder & 438 & 140 & 61.315 \\
Hutan rawa primer & 82.249 & 281 & 23.111 .923 \\
Hutan rawa sekunder & 10.473 & 234 & 2.450 .746 \\
Perkebunan sawit & 6.731 & 109 & 733.625 \\
Pertanian campuran & 18.042 & 56 & 1.010 .365 \\
Semak rawa & 477 & 30 & 14.315 \\
Semak rawa & 14.330 & 30 & 429.899 \\
Tambang & 54 & 0 & 0 \\
Tanah terbuka & 1 & 0 & 0 \\
Jumlah & 138.200 & 940 & 27.969 .594 \\
\hline
\end{tabular}

Sumber : Ballhorn dkk. (2007) dan Moder, dkk. (2008)

Tabel 2. Kandungan karbon KGM.

\begin{tabular}{cccc}
\hline Kedalaman rata-rata $(\mathrm{m})$ & Volume $\left(\mathrm{m}^{3} \times 10^{8}\right)$ & Kandungan C (Giga Ton) & Kandungan $\mathrm{CO}_{2}$ (Giga Ton) \\
\hline 1,260 & 17,900 & 0,102 & 0,370 \\
\hline
\end{tabular}

Sumber : Ballhorn dkk. (2007) 
Tabel 3. Kandungan karbon HRGMK.

\begin{tabular}{lcr}
\hline Uraian & \multicolumn{1}{|}{$\begin{array}{c}\text { Kandungan } \\
\text { Karbon } \\
\text { (ton } \mathrm{CO}_{2} \text { ) }\end{array}$} & $\begin{array}{c}\text { Kandungan } \\
\text { karbon } \\
\text { (ton } \mathrm{CO}_{2} / \mathrm{ha} \text { ) }\end{array}$ \\
\hline $\begin{array}{l}\text { Biomassa di } \\
\text { atas tanah }\end{array}$ & $27.969 .594,46$ & 202,385 \\
$\begin{array}{l}\text { Biomassa di } \\
\text { tanah }\end{array}$ & $370.000 .000,00$ & $2.677,279$ \\
\hline Jumlah & $397.969 .594,50$ & $2.879,664$ \\
\hline
\end{tabular}

Sumber : Ballhorn dkk. (2007) dan Moder dkk. (2008)

Tabel 4. Nilai karbon HRGMK.

\begin{tabular}{lcr}
\hline Uraian & $\begin{array}{c}\text { Nilai } \mathrm{CO}_{2} / \text { ha } \\
(\mathrm{Rp} / \mathrm{ha})\end{array}$ & Nilai karbon total (Rp) \\
\hline $\begin{array}{l}\text { Biomassa di } \\
\text { atas tanah }\end{array}$ & $7.488 .241,6$ & $1.034 .874 .995 .192,59$ \\
$\begin{array}{l}\text { Biomassa di } \\
\text { tanah }\end{array}$ & $99.059 .334,3$ & $13.690 .000 .000 .000,00$ \\
\hline Jumlah & $106.547 .575,9$ & $14.724 .874 .995 .192,60$ \\
\hline
\end{tabular}

Total kandungan karbon kawasan HRGMK adalah 397.969.594,50 ton $\mathrm{CO}_{2}$ ekivalen atau 2.879,664 $\mathrm{CO}_{2}$ ekivalen per hektar. Dengan mengacu pada harga karbon Ulu Masen, maka nilai ekonomi karbon HRGMK adalah US\$ 1.591.878.378,00 atau Rp. 14.002.162.211.645,00, sedangkan nilai karbon HRGMK per hektar adalah US\$ 11.518,65686 atau Rp. 104.819.777,40.

Nilai ekonomi karbon HRGMK 32,58 kali lebih besar apabila dibandingkan dengan nilai karbon Taman Nasional Gunung Halimun (Widada, 2004). Nilai karbon per hektar dari HRGMK juga lebih tinggi dari nilai ekonomi karbon hutan Gayo Lues (Rp. 2.552.635,00) (Fauzi dkk., 2011). Demikian juga apabila dibandingkan dengan nilai ekonomi karbon dari hutan di Sub DAS Konaweha Hulu (Rp. 13.351.500,00 per hektar) (Baco dkk., 2011). Nilai karbon HRGMK yang relatif tinggi apabila dibandingkan dengan TNGH, hutan Gayo Lues maupun hutan di Sub DAS Konaweha Hulu diduga terjadi karena ketiga pembanding berada di tanah mineral sehingga nilai karbon hanya berasal dari biomassa di atas tanah. Nilai karbon HRGMK sebagian besar (93\%) berasal dari kandungan karbon yang tersimpan di tanah (lahan gambut), yang tidak lain adalah Kubah Gambut Merang (KGM). Dengan demikian dapat dinyatakan bahwa kandungan karbon KGM sangat besar sehingga diperlukan upaya-upaya perlindungan dari kerusakan. Kerusakan gambut akan menyebabkan emisi gas rumah kaca ke atmosfer.

Hooijer dkk. (2006) menduga nilai emisi $\mathrm{CO}_{2}$ dari lahan gambut yang didrainase dengan menggunakan nilai emisi $\mathrm{CO}_{2}$ dari Henk Wosten (Alterra) yaitu setiap 1 meter kedalaman drainase pada lahan gambut akan mengemisikan $\mathrm{CO}_{2}$ sebesar 0,91 ton/ha/tahun. Jauhiainen dkk. (2005) menyatakan bahwa hutan rawa gambut yang didrainase di DAS Sebangau, Kalimantan menyebabkan emisi $\mathrm{CO}_{2}$ sebesar 35 ton per hektar per tahun.

Kerusakan HRGMK, terutama KGM akan menyebabkan kerugian ekonomi yang disebabkan oleh emisi karbon. Selain itu juga terjadi gangguan terhadap kemampuan hutan rawa gambut dalam menyimpan air. Mardiana (2006) dan Widodo (2011) menyatakan bahwa keberadaan perkebunan kelapa sawit di lahan gambut menyebabkan penurunan ketersediaan air wilayah sebesar 13\% apabila dibandingkan dengan apabila kawasan tersebut masih berupa hutan rawa gambut. Penuranan ketersediaan air maupun dampak ikutan dari subsidensi gambut seperti penurunan dan kehilangan produktivitas tanaman pertanian dan kehutanan (Hooijer dkk., 2013). Agus dan Subiksa (2008) menyatakan bahwa kubah gambut yang mengalami penciutan setebal satu meter akan kehilangan kemampuannya dalam menyangga air sampai $90 \mathrm{~cm}$ atau ekivalen dengan $9.000 \mathrm{~m}^{3}$ per hektar. Dengan kata lain lahan disekitarnya akan menerima $9.000 \mathrm{~m}^{3}$ air lebih banyak bila terjadi hujan deras. Sebaliknya karena sedikitnya cadangan air yang tersimpan selama musim hujan, maka cadangan air yang dapat diterima oleh daerah sekelilingnya menjadi lebih sedikit dan daerah sekitarnya akan rentan kekeringan pada musim kemarau.

Perlindungan gambut dapat memberikan perlindungan terhadap lingkungan di sekitarnya dan menjaga kualitas kehidupan manusia secara keseluruhan. Perlindungan yang diberikan bisa dinilai secara moneter. Hutan rawa gambut alami memberikan nilai ekonomi yang besar baik itu dari cadangan karbon tersimpan maupun dampak lingkungan yang tidak terjadi (loss avoided) sebagai akibat dari kerusakan kubah gambut.

\section{KESIMPULAN}

Hasil penaksiran nilai ekonomi karbon Kawasan HRGMK menunjukkan bahwa kawasan ini mempunyai nilai ekonomi karbon yang tinggi. Nilai tersebut berasal dari penilaian karbon di atas tanah (tegakan hutan) dan di bawah tanah (Kubah Gambut Merang). Hal ini menunjukkan dalam kondisi alami HRGMK memberikan jasa lingkungan bernilai ekonomi tinggi yang berupa simpanan karbon yang dapat dinilai secara moneter. Nilai ekonomi karbon HRGMK yang tinggi, terutama apabila dibandingkan dengan hutan di tanah mineral menunjukkan bahwa pelestarian HRGMK tidak bertentangan dengan pembangunan ekonomi. Menjaga kelestarian ekosistem HRGMK 
akan menjaga manfaat yang berupa nilai ekonomi karbon dan mencegah bencana lingkungan yang terjadi sebagai akibat dari kerusakan ekosistem HRGMK seperti kebakaran hutan dan lahan.

Nilai ekonomi karbon hutan rawa gambut dengan studi kasus di HRGMK menunjukkan bahwa hutan rawa gambut memberikan manfaat yang berupa jasa lingkungan dengan nilai ekonomi tinggi, sehingga pengelolaan hutan harus didasarkan pada semua manfaat yang dapat diberikan oleh hutan rawa gambut, bukan hanya manfaat yang berupa komoditas saja. Nilai ekonomi dapat digunakan sebagai acuan perumusan kebijakan pengelolaan hutan yang dapat dipertanggungjawabkan secara akademis.

\section{DAFTAR PUSTAKA}

Agus, F., dan Subiksa, I.G.M., 2008. Lahan Gambut: Potensi untuk Pertanian dan Aspek Lingkungan. Balai Penelitian Tanah Badan Penelitian dan Pengembangan Pertanian, Bogor.

Anonim, 2004. Laporan Survei Kawasan Hutan Rawa Gambut Merang Kepahiyang, Kabupaten Musi Banyuasin, Provinsi Sumatera Selatan. Wetlands InternationalIndonesia Programme, Bogor.

Anonim, 2006. IPCC Guidelines for National Greenhouse Gas Inventories, Prepared by the National Greenhouse Gas Inventories Programme. Eggleston H.S., Buendia L., Miwa K., Ngara T. and Tanabe K. (eds). Published: IGES, Tokyo.

Anonim, 2008. Merang Peat Dome. South Sumatera Forest Fire Management Project, Palembang.

Anonim, 2011. ACEH: The Ulu Masen REDD+ Pilot Project. Rights, Forest and Climate Briefing Series-October 2011. London.

Baco, L.S., Sinukaban, N., Purwanto, Y.J., Sanim, B., dan Tarigan, S.D., 2011. Valuasi Ekonomi Hutan di Sub DAS Konaweha Hulu Provinsi Sulawesi Tenggara. Agriplus, 21(2):143-151.

Ballhorn, U., Mott, C., dan Siegert, F., 2007. Peat Dome Mapping and Analysis. Draft Report. South Sumatera Forest Fire Management Project, Palembang.

Batjes, N.H., 1996. Total Carbon and Nitrogen in the Soil if the World. European Journal of Soil Science. 47:151-163.

Breaux, A., Farber, S., dan Day, J., 1995. Using Natural Coastal Wetlands Systems for Wastewater Treatment - An Economic Benefit Tranfer Analysis. Journal of Environment Management, 44:285-291.
Fauzi, Darusman, D., Wijayanto, N., dan Kusmana, C., 2011. Analisis Nilai Ekonomi Sumberdaya Hutan Gayo Lues. Jurnal Hutan dan Masyarakat, 6(1):13-20.

Furukawa, Y., Inubushi, K., Ali, M., Itang, A.M., dan Tsuruta, H., 2005. Effect of Changing Groundwater Levels Caused by Lnad-Use Changes on Greenhouse Gas Fluxes from Tropical Peatlands. Nutrient Cycling in Agroecosystems 71:81-91.

Hadi, A., Haridi, M., Inubushi, K., Purnomo, E., Razie, F., dan Tsuruta, H., 2001. Effect of Land-use Change in Tropical Peat Soil on the Microbial Pollution and Emission of Greenhouse Gases. Microbes Environment, 16:79-86.

Hadi, A., Inubushi, K., Purnomo, E., Razie, F., Yamakawa, K., dan Tsuruta, H., 2000. Effect of Land-Use Changes on Nitrous Oxide $\left(\mathrm{N}_{2} \mathrm{O}\right)$ Emission from Tropical Peatlands. Chemosphere Global Change Science, 2:347358.

Hadi, A., Inubushi, K., Furukawa, Y., Purnomo, E., Rasmadi, M. dan Tsuruta, H., 2005. Greenhouse Gas Emission from Tropical Peatlands of Kalimantan, Indonesia. Nutrient Cycling in Agroecosystems 71:73-80.

Hooijer, A, Silvius, M., Wösten, H., dan Page, S.E., 2006. PEAT- $-\mathrm{CO}_{2}$, Assessment of $\mathrm{CO}_{2}$ Emissions from Drained Peatlands in SE Asia. Delft Hydraulics Report Q3943.

Hooijer, A., Triadi, B., Karyanto, O., Page, S.E., Van der Vat, M., dan Erkens, G., 2013. Subsidence in Drained Coastal Peatlands in SE Asia : Implications for Sustainability. Extended abstract for the 14th International Peat Congress: Peatlands in Balance. International Peat Society.

Jauhiainen, J., Takahashi, H., Heikkinen, J.E.P., Martikainen, P.J., dan Vasander, H., 2005. Carbon Fluxes from a Tropical Peat Swamp Forest Floor. Global Change Biology, 11:1788-1797.

Mardiana, S,. 2006. Perubahan Sifat-sifat Tanah pada Kegiatan Konversi Hutan Alam Rawa Gambut menjadi Perkebunan Kelapa Sawit (Studi Kasus pada PT. Triomas Forest Development Indonesia Desa Panyengat Kecamatan Sungai Apit Kabupaten Siak Propinsi Riau). Skripsi Fakultas Kehutanan IPB, Bogor.

Moder, F., Siegert, F., dan Schlessinger, P., 2008. Carbon Stock Estimation in Peat Swamp Forest Area of Merang-Kepayang. Draft Report. South Sumatera Forest Fire Management Project, Palembang. 
Murdiyarso, D., dan Wasrin, U.R., 1995. Estimating land Use Change and Carbon Release from Tropical Forests Conversion Using Remote Sensing Technique. Journal of Biogeography, 2:715-721.

Murdiyarso, D., Rosalina, U, Hairiah, K., Muslihat, L., Suryadiputra, I.N.N., dan Jaya, A., 2004. Petunjuk Lapangan Pendugaan Cadangan Karbon pada Lahan Gambut. Proyek Climate Change, Forest and Peatlands in Indonesia. Wetlands International-Indonesia Programme dan Wildlife Habitat Canada, Bogor.

Murdiyarso, D., Dewi, S., Agus, F., Suyanto, Iskandar, H., Suryadiputra, N., Noor, Y.R., Rais, D., Ekadinata, A., Herman, T., Abla, I., Aboesoemono, I., dan van Hofwegen, P., 2007. Peatland Land Use Change Strategy. IFCA Study 5/WP 2.

Pirard, R., 2005. Pulpwood Plantations as Carbon Sinks in Indonesia: Methodological Challenge and Impact on Livelihoods. In Murdiyarso, D. and Herawati, H. (Eds.). Carbon Forestry : Who Will Be Benefit? Proceeding of Workshop on carbon Sequestrations and Sustainable Livelihoods. Center for International Forestry Research, Bogor.
Plummer, M.L., 2009. Assessing Benefit Transfer for The Valuation of Ecosystem Services. Frontiers in Ecology and the Environment, 38:38-45.

Putro, H. R., 2008. Peluang Perdagangan Karbon di Kawasan Gambut Merang Sumatera Selatan. Laporan Akhir. South Sumatera Forest Fire Management Project, Palembang.

Solichin, 2010. Pengukuran Emisi Karbon di Kawasan Hutan Rawa Gambut Merang. Merang REDD Pilot Project, Palembang.

Wahyunto, Ritung, S., Suparto, dan Subagjo, H., 2005. Sebaran Gambut dan Kandungan Karbon di Sumatera dan Kalimantan 2004. Wetland Internasional - Indonesia Programme, Bogor.

Widada, 2004. Nilai Manfaat Ekonomi dan Pemanfaatan Taman Nasional Gunung Halimun bagi Masyarakat. Disertasi Sekolah Pascasarjana IPB, Bogor.

Widodo, I.S., 2011. Estimasi Nilai Lingkungan Perkebunan Kelapa Sawit Ditinjau dari Neraca Air Tanaman Sawit. Skripsi Fakultas Matematika dan Ilmu Pengetahuan Alam IPB, Bogor. 